\title{
Cutis laxa
}

INSERM

\section{Source}

INSERM. (1999). Orphanet: an online rare disease and orphan drug data base. Cutis laxa. ORPHA:209

Cutis laxa (CL) is an inherited or acquired connective tissue disorder characterized by wrinkled, redundant and sagging inelastic skin associated with skeletal and developmental anomalies and, in some cases, with severe systemic involvement. Several different forms of inherited CL have been described, differentiated on the basis of the mode of inheritance and differences in the extent of internal organ involvement, associated anomalies and disease severity. 